\title{
The distribution of amosite asbestos in the periphery of the normal human lung
}

\author{
Andrew Churg
}

\begin{abstract}
Although theoretical models and experiments on animals exist that predict the distribution of asbestos fibres in the lung, there are few studies in man that relate to this question and they have generated contradictory results. To examine this distribution analytical electron microscopy was employed to determine the amosite fibre concentration, size, surface area, and mass in 29 circumferential sites around the periphery of a mid-sagittal slice from nine morphologically normal left lungs of heavily exposed shipyard workers and insulators. Fibre concentrations were heaviest in the apical segment of the upper lobe, and low concentrations were seen in the posterior basal portion of the lower lobe. Overall, the upper lung zones had significantly greater concentrations than the lower lung zones. Fibre length was shortest in the anterior portion of the upper lobe, greater in the lingula, and greatest in the posterior basal portion of the lower lobe; fibre length overall was significantly greater in the lower compared with the upper zones. Aspect ratio followed a similar pattern. Distinct geographic runs of high or low concentrations and long or short lengths and aspect ratios were present. No consistent distribution patterns for fibre width, surface area, or mass were found. It is concluded that: (1) in the periphery of the normal lung, concentration of amosite fibres is greatest in the apex and least in the peripheral lower lobe. This distribution is the opposite of what would be expected from the known distribution of asbestosis (peripheral lower zone); nor does it correlate with bronchial pathlength or branch number, contrary to predictions from studies on animals and theoretical models; (2) fibre length and related parameters show a distribution opposite to that of fibre concentration and again do not correlate with theoretical predictions.
\end{abstract}

Department of Pathology and University Hospital, University of British Columbia, Vancouver, BC, Canada

A Churg
Diseases related to asbestos do not occur randomly in different parts of the lung but generally have distinct anatomical distributions. Asbestosis, for example, is most severe in the peripheral lower zones. Benign pleural plaques and visceral pleural fibrosis are also predominantly diseases of the lower zone. This may be true of malignant mesothelioma, at least in its early phases. It has also been suggested that lung cancer in those with exposure to asbestos is more common in the lower lobes, whereas lung cancer in ordinary cigarette smokers is more common in the upper lobes.'

That the geographic distribution of asbestos induced disease should be related to the underlying distribution of asbestos fibres within the lung is a reasonable proposition, but one that has been sparsely examined. Predictions of deposition of fibres as a function of structure of the lung have been made from theoretical calculations, ${ }^{2}$ and some correlative data on animals exist. Pinkerton et al showed, using inhalation of chrysotile asbestos in rats, that deposition of fibre in any part of the lung is an inverse function of pathlength and number of airway branch points leading to the area in question; thus the shorter the path and the fewer the airway branches, the greater the concentration of fibres deposited. They also observed that the shorter the pathlength, the greater the proportion of long fibres. ${ }^{34}$ These findings are in good agreement with theory. ${ }^{2}$ Of note in the studies of Pinkerton et al ${ }^{34}$ is that the regions receiving the greatest fibre burden also showed the greatest degree of fibrosis, emphasising the relation between distribution of fibres and pathological reactions.

In man there is little detailed information about distribution of fibres within the lung, and much of what exists is contradictory. Sebastien et al, ${ }^{5}$ using light and electron microscopy and counting both amphibole and chrysotile fibres, suggested that in heavily exposed workers with asbestosis, the peripheral lower lobes had the lowest concentrations of fibres but they had the longest. This distribution was not seen in those without asbestosis. Morgan and Holmes $^{67}$ performed a detailed study of the periphery of the lung in three asbestos workers by light microscopy. In one worker the greatest concentrations were found in the upper zones, in a second in the lower zones, and in a third there was no clear predominance. Churg and Wiggs ${ }^{8}$ examined four 
different sites (two central, two peripheral, upper and lower lobe) in lungs from patients with mesothelioma or carcinoma and found that, although there were quite distinct reproducible (and somewhat surprising-see Discussion) patterns of differences in fibre size, there were no obvious differences in concentration among the sites.

The studies on man have in many instances suffered from methodological problems, from comparison of different types of asbestos fibres, and from the use of samples prepared from non-comparable regions of the lung. To evaluate the distribution of asbestos fibres more accurately, we examined distribution of fibres by electron microscopy in nine shipyard workers and insulators using a carefully defined sampling scheme and counting only one type of fibre.

\section{Materials and methods} CASE SELECTION

Cases for this study were selected from a large group of lungs obtained at necropsy from shipyard workers and insulators from the Pacific northwest, all with a history of heavy exposure to asbestos. To be included in the study, the following requirements needed to be met:

(1) A mid-sagittal or near mid-sagittal slice of left lung was available. This requirement ensured that exactly the same areas of the lung could be sampled in each case.

(2) The lung was grossly and microscopically close to normal. Minor amounts of emphysema and pneumonia were allowed. This requirement was imposed to rule out differences related to specific diseases such as asbestosis.

(3) Initial evaluation by analytical electron microscopy of a single large sample showed an amosite concentration of at least 300000 fibres per g dry lung. This requirement ensured a fibre concentration high enough to allow the subsequent analysis to be completed in a reasonable time. Restriction to amosite only was imposed because different types of asbestos fibres have different size characteristics and might be distributed differently within the lung.

\section{SAMPLING}

The entire periphery of the left lung was sampled sequentially using blocks of approximately $1.5 \times 1$ $\times 1 \mathrm{~cm}$ size. Because the various lungs used were different sizes and slightly different shapes, some lungs provided more pieces of tissue than others, so that in some instances two or three samples were combined. This resulted in the scheme shown in fig 1 , in which 29 regions of the peripheral lung were examined.

ANALYTICAL ELECTRON MICROSCOPY

Each sample was dissolved in bleach and the fibres

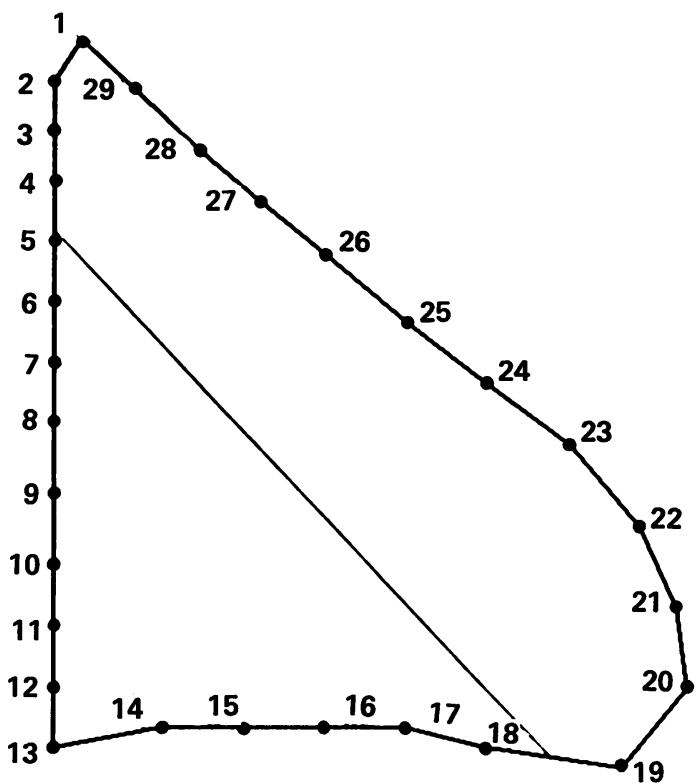

Figure 1 Base map of mid-sagittal slice of left lung to show sampling sites. Straight line is the major fissure. 1 Apex of upper lobe; 2-4 posterior upper lobe; 5 superior tip of lower lobe; 6-12 posterior lower lobe; 13 posterior tip of lower lobe (posterior basal segment); 14-17 basal lower tip; 18 anterior tip lower lobe; 19 lingular tip; 20-24 anterior edge of lingula; 25-29 anterior edge of upper lobe (anterior and apical segments). Note that the division between lingula and anterior segment of the upper lobe (samples 24-25) is approximate.

were collected for analysis according to previously published protocol. ${ }^{8}$ Examination was performed in a Philips $400 \mathrm{~T}$ electron microscope fitted with a Kevex 7000 energy dispersive $x$ ray spectrometer. For each sample site approximately 50 amosite fibres were identified and measured, except in a few sites where fibre concentration was extremely low and less fibres were counted. Fibre concentrations were expressed in terms of dry lung; the wet:dry ratio was determined by taking additional samples of lung and drying them to constant weight.

\section{STATISTICAL ANALYSIS}

Fibre sizes and related parameters for each site were calculated as geometric means because the data showed the usual log normal distribution seen with fibre sizes. As the concentrations as well as sizes varied considerably from case to case, and because my interest was in the relative change from site to site rather than the absolute value, the mean values of dimensions over all the cases were calculated, and the data for each individual case were adjusted so that all cases had the same mean. Comparisons were then performed on these values using analysis of variance with initial log transformation of the data as required 
to produce normal distributions. To evaluate whether there were runs (sequences) of high or low values, the Wald-Wolfowitz runs test was employed (see Discussion). The SYSTAT system was used for all analyses. ${ }^{9}$ Bonferroni type corrections for multiple comparisons were used where appropriate. ${ }^{10}$

To facilitate understanding of the results, the data are presented in two ways; as a table with means and SE indicated, and as maps in which the diameter of the circles is proportional to the appropriate dimension for that sample site.

\section{Results}

The mean age (SEM) of the patients was 62 (5), the mean pack-years of smoking 36 (13), and the mean years of exposure 21 (6).

Figure 1 shows the basic lung map representing a mid-sagittal slice of left lung with the 29 sampling sites displayed.

The table shows the data by site in numerical form. Figure 2a shows a map of mean amosite fibre concentration in the different sampling sites. The highest concentrations of fibres were found in the apex and anterior upper lobe $(p<0.001$ comparing these sites with the rest of the lung) with much lower concentrations in the posterior and basal lower lobes. Arbitrarily dividing the lung into upper and lower zones between posterior samples 6 and 7 and anterior samples 24 and 25 , gave a fibre concentration in the upper zone significantly greater than that in the lower zone $(\mathrm{p}<0.01)$.
Figures 2a-f are maps of geometric mean fibre concentration, length, width, aspect ratio, surface area, and mass. The longest fibres and the fibres with the highest aspect ratio were found in the lower zones of both upper and lower lobes; using the same arbitrary division, the difference between upper and lower zones was significant ( $p<0.02$ for length, $p<$ 0.01 for aspect ratio). No obvious patterns were seen for fibre widths, surface areas, or masses.

The Wolf-Wolfowitz runs test confirmed the visual impression of distinct runs of high or low values (compared to the overall mean) for concentration ( $\mathrm{p}<0.004)$, length $(\mathrm{p}<0.015)$, and aspect ratio $(p<0.004))$. No runs were seen for width, surface area, or mass.

\section{Discussion}

In this study I have examined in a detailed fashion the distribution of fibres in the periphery of nine lungs from workers with heavy exposure to amosite asbestos. Some clear patterns emerged; fibre concentration tended to be greatest at the apex of the lung, whereas the longest and highest aspect ratio fibres were seen in the lower zones. It was also apparent that large scale regional differences within the periphery of the lung were most clearly related to fibre length and fibre concentration; this was evident on inspection of the maps and confirmed by the statistically significant run tests.

Fibre width, surface area, and mass did not show

Mean values ( $S E M$ ) for fibres for each site of lung

\begin{tabular}{|c|c|c|c|c|c|c|c|c|c|c|c|c|}
\hline \multirow{2}{*}{$\frac{\text { Site }}{1}$} & \multicolumn{2}{|c|}{$\begin{array}{l}\text { Concentration } \\
\text { fibres/g dry lung } \\
\times 10^{6}(S E M)\end{array}$} & \multicolumn{2}{|c|}{$\begin{array}{l}\text { Length } \\
\text { microns ( } S E \text { ) }\end{array}$} & \multicolumn{2}{|c|}{$\begin{array}{l}\text { Width } \\
\text { microns ( SE) }\end{array}$} & \multicolumn{2}{|c|}{ Aspect } & \multicolumn{2}{|c|}{$\begin{array}{l}\text { Surface } \\
\text { microns }{ }^{2} \text { (SE) }\end{array}$} & \multicolumn{2}{|c|}{$\begin{array}{l}\text { Mass } \\
g \times 10^{-15} \\
(S E)\end{array}$} \\
\hline & $5 \cdot 6$ & $(1.5)$ & $5 \cdot 1$ & $(0 \cdot 3)$ & 0.21 & $(0.01)$ & 25.9 & $(2 \cdot 5)$ & 3.0 & $(0 \cdot 2)$ & 380 & (28) \\
\hline 2 & & $(0 \cdot 7)$ & $5 \cdot 7$ & $(0 \cdot 4)$ & 0.22 & $(0.02)$ & $27 \cdot 7$ & $(2 \cdot 3)$ & 3.5 & $(0 \cdot 4)$ & 450 & (58) \\
\hline 3 & & $(0 \cdot 6)$ & $5 \cdot 2$ & $(0.4)$ & 0.21 & $(0.01)$ & 26.5 & $(2 \cdot 2)$ & 3.0 & $(0 \cdot 3)$ & 390 & (39) \\
\hline 4 & & $(0.6)$ & $5 \cdot 1$ & $(0 \cdot 5)$ & 0.22 & $(0.01)$ & 25.0 & $(1.9)$ & 3.0 & $(0 \cdot 2)$ & 390 & (28) \\
\hline 5 & 3.0 & $(1 \cdot 2)$ & $4 \cdot 3$ & $(0 \cdot 6)$ & 0.20 & $(0.01)$ & $23 \cdot 2$ & $(3 \cdot 6)$ & $2 \cdot 7$ & $(0 \cdot 3)$ & 330 & (27) \\
\hline 6 & $3 \cdot 1$ & $(0 \cdot 6)$ & $5 \cdot 0$ & $(0 \cdot 2)$ & 0.22 & $(0.02)$ & $25 \cdot 8$ & $(2 \cdot 6)$ & $2 \cdot 9$ & $(0 \cdot 3)$ & 370 & (48) \\
\hline 7 & 2.5 & $(0 \cdot 6)$ & $5 \cdot 2$ & $(0 \cdot 6)$ & 0.22 & $(0.02)$ & 24.9 & $(2 \cdot 0)$ & $3 \cdot 4$ & $(0.5)$ & 460 & (65) \\
\hline 8 & $3 \cdot 1$ & $(0.2)$ & $5 \cdot 4$ & $(0.5)$ & 0.22 & $(0.02)$ & $27 \cdot 9$ & $(2.9)$ & 3.0 & $(0 \cdot 5)$ & 390 & (65) \\
\hline 9 & $2 \cdot 1$ & $(0.5)$ & 6.0 & $(0.3)$ & 0.22 & $(0.03)$ & $31 \cdot 1$ & $(2 \cdot 9)$ & 3.0 & $(0 \cdot 5)$ & 530 & (120) \\
\hline 10 & $2 \cdot 8$ & $(1 \cdot 0)$ & $5 \cdot 5$ & $(0 \cdot 4)$ & 0.20 & $(0.01)$ & $31 \cdot 7$ & (3.4) & 3.0 & $(0 \cdot 1)$ & 370 & (14) \\
\hline 11 & $3 \cdot 2$ & $(0.9)$ & $6 \cdot 1$ & $(0 \cdot 6)$ & 0.22 & $(0.01)$ & $27 \cdot 1$ & $(2 \cdot 0)$ & 3.5 & $(0 \cdot 2)$ & 470 & (43) \\
\hline 12 & $2 \cdot 8$ & $(0.9)$ & 5.9 & $(0 \cdot 8)$ & 0.20 & $(0.01)$ & $27 \cdot 7$ & $(1.5)$ & 3.0 & $(0 \cdot 3)$ & 390 & (39) \\
\hline 13 & $2 \cdot 2$ & $(0.7)$ & $4 \cdot 8$ & $(0 \cdot 3)$ & $0 \cdot 18$ & $(0.01)$ & $29 \cdot 1$ & $(2 \cdot 5)$ & 2.5 & $(0 \cdot 2)$ & 300 & (34) \\
\hline 14 & $2 \cdot 7$ & $(0.8)$ & $4 \cdot 8$ & $(0 \cdot 3)$ & 0.19 & $(0.01)$ & 27.9 & $(3 \cdot 0)$ & $2 \cdot 7$ & $(0 \cdot 2)$ & 360 & (39) \\
\hline 15 & $2 \cdot 1$ & $(0.5)$ & 5.9 & $(0 \cdot 6)$ & 0.21 & $(0.01)$ & $30 \cdot 0$ & $(3 \cdot 3)$ & 3.5 & $(0 \cdot 3)$ & 460 & (44) \\
\hline 16 & $2 \cdot 6$ & $(0 \cdot 6)$ & $5 \cdot 0$ & $(0 \cdot 3)$ & $0 \cdot 19$ & $(0.01)$ & $27 \cdot 2$ & $(1 \cdot 7)$ & $2 \cdot 7$ & $(0 \cdot 4)$ & 340 & (57) \\
\hline 17 & $2 \cdot 6$ & $(0.9)$ & $5 \cdot 2$ & $(0 \cdot 6)$ & $0 \cdot 19$ & $(0.02)$ & 28.4 & $(2.9)$ & $3 \cdot 1$ & $(0 \cdot 6)$ & 420 & (83) \\
\hline 18 & $3 \cdot 7$ & $(1.0)$ & $5 \cdot 0$ & $(0 \cdot 3)$ & $0 \cdot 19$ & $(0.01)$ & $29 \cdot 1$ & $(1.9)$ & $2 \cdot 7$ & $(0 \cdot 3)$ & 340 & (38) \\
\hline 19 & $3 \cdot 8$ & $(1 \cdot 6)$ & $5 \cdot 1$ & $(0 \cdot 3)$ & 0.21 & $(0.01)$ & $27 \cdot 1$ & $(2 \cdot 4)$ & 3.0 & $(0 \cdot 2)$ & 390 & (18) \\
\hline 20 & $3 \cdot 0$ & $(1 \cdot 1)$ & $5 \cdot 3$ & $(0 \cdot 4)$ & $0 \cdot 19$ & $(0.01)$ & $28 \cdot 1$ & $(2 \cdot 1)$ & $3 \cdot 1$ & $(0 \cdot 3)$ & 400 & (35) \\
\hline 21 & $3 \cdot 2$ & $(1 \cdot 1)$ & $5 \cdot 3$ & $(0.4)$ & 0.20 & $(0.02)$ & $29 \cdot 0$ & $(1 \cdot 8)$ & $3 \cdot 0$ & $(0.4)$ & 390 & $(60)$ \\
\hline 22 & 4.0 & $(1 \cdot 0)$ & 5.9 & $(0 \cdot 7)$ & 0.19 & $(0.01)$ & 33.4 & $(3.5)$ & $3 \cdot 2$ & $(0 \cdot 4)$ & 370 & (47) \\
\hline 23 & $2 \cdot 8$ & $(0.5)$ & $5 \cdot 4$ & $(0 \cdot 4)$ & 0.20 & $(0.01)$ & $28 \cdot 2$ & $(1 \cdot 7)$ & $3 \cdot 3$ & $(0.4)$ & 440 & (68) \\
\hline 24 & $2 \cdot 2$ & $(0.9)$ & $4 \cdot 6$ & $(0 \cdot 3)$ & 0.21 & $(0.02)$ & $23 \cdot 4$ & $(2 \cdot 2)$ & 2.9 & $(0 \cdot 3)$ & 430 & (61) \\
\hline 25 & 1.9 & $(0.5)$ & $4 \cdot 4$ & $(0 \cdot 3)$ & $0 \cdot 19$ & $(0.01)$ & $24 \cdot 7$ & $(2 \cdot 1)$ & $2 \cdot 6$ & $(0 \cdot 3)$ & 340 & (34) \\
\hline 26 & $2 \cdot 6$ & $(0.6)$ & & $(0.4)$ & 0.20 & $(0.02)$ & 26.6 & $(1.9)$ & $2 \cdot 6$ & $(0 \cdot 3)$ & 330 & (38) \\
\hline 27 & & $(0.9)$ & $4 \cdot 8$ & $(0 \cdot 2)$ & 0.23 & $(0.02)$ & 22.4 & $(1.5)$ & $3 \cdot 1$ & $(0 \cdot 3)$ & 450 & (51) \\
\hline 28 & & $(2 \cdot 4)$ & $4 \cdot 8$ & $(0 \cdot 2)$ & 0.22 & $(0.02)$ & 23.9 & $(1.9)$ & $2 \cdot 9$ & $(0 \cdot 3)$ & 410 & (53) \\
\hline 29 & $4 \cdot 5$ & $(1 \cdot 0)$ & $4 \cdot 8$ & $(0 \cdot 2)$ & 0.22 & $(0.01)$ & $23 \cdot 7$ & $(1 \cdot 4)$ & 2.9 & $(0 \cdot 2)$ & 380 & (33) \\
\hline
\end{tabular}



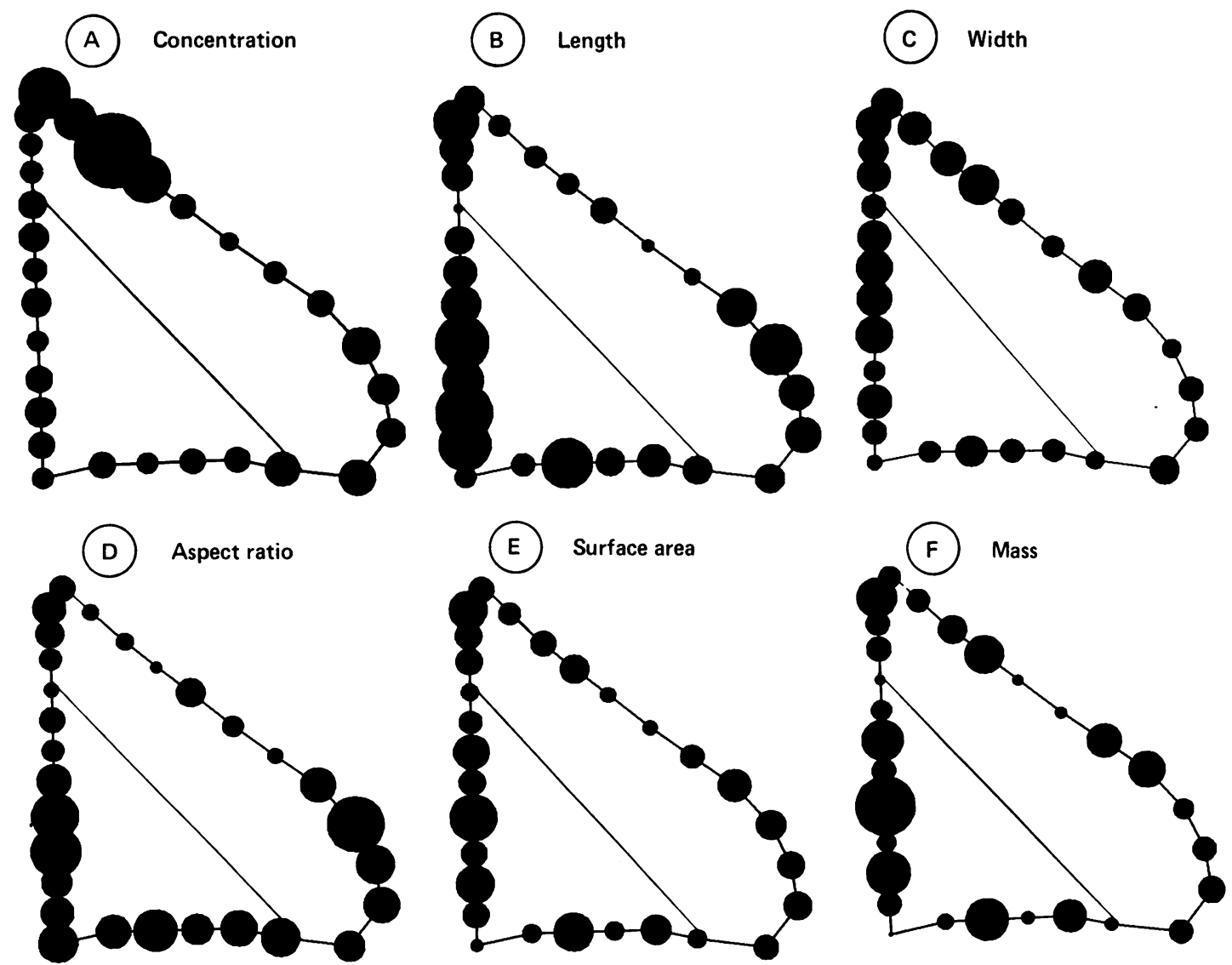

Figure 2 (a) Map of mean fibre concentration by site. Diameter of spot is proportional to amosite concentration (fibres $\times 10^{6} \mathrm{~g}$ dry lung); (b) mean fibre length by site. Diameter of spot is proportional to mean fibre length (microns); (c) mean fibre width by site. Diameter of spot is proportional to mean fibre width (microns); (d) mean fibre aspect ratio by site. Diameter of spot is proportional to mean fibre aspect ratio; $(e)$ mean fibre surface area by site. Diameter of spot is proportional to mean fibre surface area $\left(\right.$ microns $\left.^{2}\right) ;(f)$ mean fibre mass by site. Diameter of spot is proportional to mean fibre mass $\left(g \times 10^{-15}\right)$.

generalised trends around the periphery of the lung, although small "hot spots" and "cold spots" existed for these size parameters, and also for length and aspect ratio. In particular the superior and posterior tips of the lower lobe tended to accumulate very short narrow fibres. Relatively few fibres were seen along the anterior surface of the upper lobe in the region of the junction between anterior segment of the upper lobe and superior segment of the lingula and they were short. These findings may reflect low levels of ventilation to some of the most distal portions of various segments of the lung, ${ }^{67}$ but other factors must also apply, as fibre concentration was relatively high in two other distal portions, the apex and the lingular tip, and long fibres were found in the posterior basal portions of the lung and lingular tip.

Theoretical predictions ${ }^{2}$ as well as the data of Pinkerton et $a^{34}$ for the rat suggest that the longer the airway path length the less the fibre deposition and the shorter the mean fibre length. Clearly a model based on decreasing fibre concentration with increasing pathlength, however, will not explain the data on man. Although the difference in concentration between the apex and posterior base fits this theory (the difference in pathlength is some two to three fold, ${ }^{11}$ and unpublished data) the superior segment of the lower lobe has approximately the same pathlength as the ape ${ }^{11}$ but considerably fewer fibres. Conversely, there appears to be a trend to fibre accumulation in the lingular tip, a region which has a very long pathlength. A similar failure to match predictions based on airway pathlength is seen for the data on fibre length. For the most part the longest fibres were found in regions with the greatest airway pathlengths.

In the rat, pathlength and number of airway branches tend to correlate. ${ }^{3412}$ Although detailed published data on this point in human material are 
difficult to find, examination of casts of human lungs shows that, despite marked differences in pathlength, there are only slightly greater numbers of branch points leading to the posterior basal segment compared with the apex. In contrast, the superior segment of the lower lobe is served by slightly fewer or the same number of branches as the apical segment of the upper lobe (A Churg, unpublished data). Again it is clear that branch numbers will not explain the data.

It has been repeatedly demonstrated in animals that non-fibrous particles tend to accumulate in the apex of the lung despite the fact that ventilation is greatest to the lower zones. ${ }^{12-14}$ In a recent study examining non-fibrous particles derived from ambient air in the lungs of persons in the general population, we found that these too accumulated in the apical segment, ${ }^{11}$ and this has also been reported for persons inhaling inert radiolabelled particles. ${ }^{15}$ It would appear that fibres show the same trend. Unfortunately a clear explanation for this process with non-fibrous particles is lacking; the effect appears to be independent of gravitational orientation ${ }^{1314}$ but might relate to increased dwell time of inhaled gas in regions with lower ventilation. ${ }^{15}$

It is also possible that redistribution of fibres after inhalation plays an important part in determining the ultimate pattern of fibre distribution. The data of Pinkerton $e t \mathrm{al}^{34}$ on animals are based on acute exposures, but even in experimental animals account must be taken of patterns of long term clearance. Morgan and Holmes, ${ }^{16}$ using rats, found that over the course of several months asbestos fibres tended to redistribute themselves into subpleural "hot spots" with areas of very low concentration in between. There is some evidence to suggest that redistribution of fibres also occurs in man. Churg and Wiggs ${ }^{8}$ observed that, in the lungs of heavily exposed mesothelioma cases, the peripheral posterior upper lobe invariably contained longer fibres than the central upper lobe, a distribution exactly opposite to that predicted by theoretical models of acute deposition and to the data of Pinkerton et al for rats. ${ }^{34}$ Proof that redistribution occurs in man will require examination of the deep parenchyma as well as the periphery.

Whatever the mechanism producing the distribution of fibres in the periphery of the lung, the observations presented here raise questions concerning the relation of fibre concentration and size to disease. As noted in the introduction, most asbestos induced disease tends to be more severe or to start in the lower zones. Given that some diseases-for example, asbestosis (diffuse interstitial fibrosis)-are related to inhaled or retained fibre dose, it is difficult to explain the current results unless fibre size (length) is considerably more important than fibre concentration in initiation of disease. There is much evidence that long fibres are both more carcinogenic and more fibrogenic than short fibres in animals, ${ }^{17-19}$ but the relative roles of long and short fibres in man are unclear. It is also possible that the current findings represent the pattern seen in non-diseased lungs, and that the presence of pathological abnormalities such as fibrosis changes the distribution pattern of inhaled fibres.

This work was supported by a grant from the National Cancer Institute of Canada and grant MA7820 from the Medical Research Council of Canada.

Requests for reprints to: Andrew Churg, $M D$, Department of Pathology, University of British Columbia, 2211 Wesbrook Mall, Vancouver, BC V6T 1W5, Canada.

1 Churg A. Neoplastic asbestos-induced diseases. In: Churg A, Green FHY, eds. Pathology of Occupational Lung Disease. New York: Igaku-Shoin Medical Publishers, 1988:282-4.

2 Ashgarian B, Yu CP. Deposition of inhaled fibrous particles in the human lung. Journal of Aerosol Medicine 1988;1:37-50.

3 Pinkerton KE, Plopper CG, Mercer RR, et al. Airway branching patterns influence asbestos fiber location and the extent of tissue injury in the pulmonary parenchyma. Lab Invest 1986; 55:688-95.

4 Pinkerton KE, Yu C-P. Intrapulmonary airway branching and parenchymal deposition of chrysotile asbestos fibers. In: Wehner AP, Felton D-L, eds. Biological Interaction of Inhaled Mineral Fibers and Cigarette Smoke. Columbus, Ohio: Battelle Press, 1989:211-22.

5 Sebastien P, Fondimare A, Bignon J, Monchaux G, Desbordes $\mathrm{J}$, Bonnaud G. Topographic distribution of asbestos fibres in human lung in relation to occupational and non-occupational exposure. In: Walton WH, McGovern B, eds. Inhaled particles IV. New York: Pergamon Press, 1977:435-44.

6 Morgan A, Holmes A. Distribution and characteristics of amphibole asbestos fibres, measured with the light microscope, in the left lung of an insulation worker. $\mathrm{Br} J$ Ind Med 1983;40:45-50.

7 Morgan A, Holmes A. The distribution and characteristics of asbestos fibres in the lungs of Finnish anthophyllite workers. $B r J$ Ind Med 1984;33:62-75.

8 Churg A, Wiggs B. Accumulation of long asbestos fibers in the peripheral upper lobe in cases of mesothelioma in man. Am J Ind Med 1987;11:563-70.

9 Wilkinson L. SYSTAT: The System for Statistics. Evanston, Il: SYSTAT Inc, 1988.

10 Shaffer JP. Modified sequentially rejective multiple test procedures. Journal of the American Statistical Association 1986;81:826-31.

11 Churg A, Wright JL, Stevens B. Exogenous mineral particles in the human bronchial mucosa and lung parenchyma; I. Nonsmokers in the general population. Exp Lung Res 1990;16: 169-75.

12 Raab OG, Yeh H-C, Newton GJ, Phalen RF, Velasquez DJ. Deposition of inhaled monodisperse aerosols in small rodents. In: Walton WH, McGovern B, eds. Inhaled particles IV. New York: Pergamon Press, 1977:3-21.

13 Brain JD, Valberg PA. Deposition of aerosol in the respiratory tract. Am Rev Respir Dis 1979;120:1325-73.

14 Sneddon SL, Brain JD. Persistent apex to base gradients of aerosol deposition in rats. Respir Physiol 1981;46:113-24.

15 Trajan M, Logus JW, Emms EG, Man SPF. Relationship between regional ventilation and aerosol deposition in tidal breathing. Am Rev Respir Dis 1984;130:64-70.

16 Morgan A, Evans JC, Holmes A. Deposition and clearance of inhaled fibrous minerals in the rat. Studies using radioactive tracer technique. In: Walton WH, McGovern B, eds. Inhaled particles IV. New York: Pergamon Press, 1977:259-74.

17 Stanton MF, Layard M, Tegeris A, Miller E, May M, Morgan $\mathrm{E}$, et al. Relation of particle dimension to carcinogenicity in amphibole asbestoses and other fibrous minerals. J Natl Cancer Inst 1981;67:965-75.

18 Davis JMG, Addison J, Bolton RE, Donaldson K, Jones AD, Smith $T$. The pathogenicity of long versus short fibre samples of amosite asbestos administered to rats by inhalation and intraperitoneal injection. Br J Exp Pathol 1986;67:415-30.

19 Davis JMG, Jones AF. Comparison of the pathogenicity of long and short fibres of chrysotile asbestos in rats. Br J Exp Pathol 1988;69:717-37.

Accepted 20 March 1990 